\title{
THE IMPACT OF SOCIAL NETWORKS ON SAUDI RESIDENTS LIVING IN THE UNITED STATES
}

\author{
John J. Scarpino, Robert Morris University, scarpino@rmu.edu \\ Ali Abdullah Alshif, Robert Morris University, aaast26@mail.rmu.edu
}

\begin{abstract}
Social networking sites have impacted how we function as a global society, and these sites also break down the walls within the culture where it is used. The methods and means of social networking are changing every day, worldwide - becoming more dynamic, more functional, and more easily integrated into everyday life. This research paper aims to demonstrate how social networking has impacted Saudi Arabian residents living in the U.S. and how these residents' social networking skills are being used to close the gap of time and space beyond their homeland.
\end{abstract}

Keywords: Saudi, Saudi Arabian, Saudi Students, Foreign U.S. Residents, Social Network, Social Media, WhatsApp.

\section{INTRODUCTION}

Social networking, smartphones, and social media applications are becoming increasingly popular and are used by millions of people for many reasons. Social networking allows users to be connected with their families and friends, and provides them with several functionalities such as sharing photos, videos, news, daily status updates, and other special topics. Some social networking and smartphone applications specialize in a single domain of proposed usage, such as dating, social/friendly relationships, or business acquaintance.

Boyd and Ellison (2007, para. 4) define a social network as a "web-based service that allows individuals to (1) construct a public or semi-public profile within a bounded system, (2) articulate a list of other users with whom they share a connection, and (3) view and traverse their list of connections and those made by others within the system. The nature and nomenclature of these connections may vary from site to site."

The stakes are being raised far beyond who has access and even whose voices are heard or silenced in the evolving public and private spaces of digital communications. These global digital networks are not just collapsing the boundaries between carrier and content, between personal communication and customized broadcasting, between the business of culture and the culture of business, between production and consumption, between the private sphere and the public sphere, and between the previously separated sectors of re-sources, manufacturing, finance, education entertainment, and so forth. They are radically altering how society is organized and managed in space and time (Menzies, 1999).

Globalization, the Internet, and social media have "shrunk" the world's view of time and distance, and have positive and negative implications for society. Modern communication (and social networks in particular) allows people who live large distances from each other to communicate regularly - for instance, Saudi Arabian people ("Saudis") living in the United States whose family members reside in the Middle East. Social networks also connect an individual to large groups on a more intimate level than would be achieved through a speech or letter. Even the press and political figureheads in Saudi Arabia have embraced social media as a means of interacting with their audiences and constituents (Ghanem, 2012). Conversely, some people choose to spend most of their time participating in online social networking as an alternative to meaningful conversation and face-to-face interaction. This may cause their relationship with friends and family to deteriorate, and in the most extreme cases, it may even affect the social network user's physical wellbeing. Saudi society is known for having strong relationships that bond family members and friends across generations. It is possible that Saudis who live in Saudi Arabia and aggressively participate in social networks may loosen their connection to their local family members while strengthening their connection to family members and friends who live abroad. 


\section{Issues in Information Systems}

Volume 14, Issue 1, pp.72-81, 2013

There are thousands of social networks and applications available worldwide, but a social network's popularity is determined by how well it meets the user's personal needs and desires. A social network can be affected by cost, time, culture, geography and other factors. For example, WhatsApp is a smartphone-based application that allows multimedia downloads and text messaging without having to pay a short message service (SMS) fee; this feature makes WhatsApp quite popular in Saudi Arabia. While WhatsApp meets the needs of niche communities, other social networks are used widely across many cultures. The most prominently used social networking tool worldwide - Facebook - supports several languages and is used for online dating, playing games, sharing photos and video, chatting, event planning, and posting personal updates for family and friends to see. Another popular tool, Twitter, provides 140-character text-based snapshots ("tweets") of user thoughts, opinions, and current events, with the opportunity for users to "re-tweet," or re-post, what they see and track conversations from across the globe.

\section{Background}

Social networking tools (also known as "social media") were created the mid-1990's. A novelty at first, these tools rapidly flew into frequent use by the general public as the Internet became accessible to anyone with a dial-up connection. In 1994, a web-hosting and -publishing tool called Geocities gave the public an opportunity to create websites about personal topics of interest, which included chat and bulletin board features. One year later, a public chat room called TheGlobe.com was created, which gave participants with similar interests the chance to share personal experiences and content through an online format. SixDegrees.com was founded in 1997, and followed a "six degrees of separation" methodology that allowed users to send messages to a list of their friends, family, coworkers and acquaintances, and then search other users' contact lists as a means of forming new relationships. SixDegrees.com and Friendster were precursors to the concept of "friending" as used in modern popular social networks such as LinkedIn, MySpace and Facebook (Simon, 2009). While founded in the 1980's, America Online (AOL) paved the way for modern social networking around the turn of the $21^{\text {st }}$ Century with various styles of interactive chat rooms, instant messaging, innovative news content, photo and video downloads, and online bulletin boards

In the first decade of the 2000's, social media became even more interactive and focused on visual content. Sites such as Instagram, Pinterest, and YouTube allowed users to upload, modify, share, and comment on photos and video. FourSquare mapped where users were geographically located in relation to their friends at any given moment; Tumblr hosted users' short-form blog content and photos for other users to comment on; and Mashable condensed hot topics and trending content about social media and mobile technology into a quick-view dashboard for anyone to view. However, Facebook, MySpace and Twitter remained the most popular global social networks. Figure 1 shows the number of social network users between 2002 and 2006 ("The history," 2010).

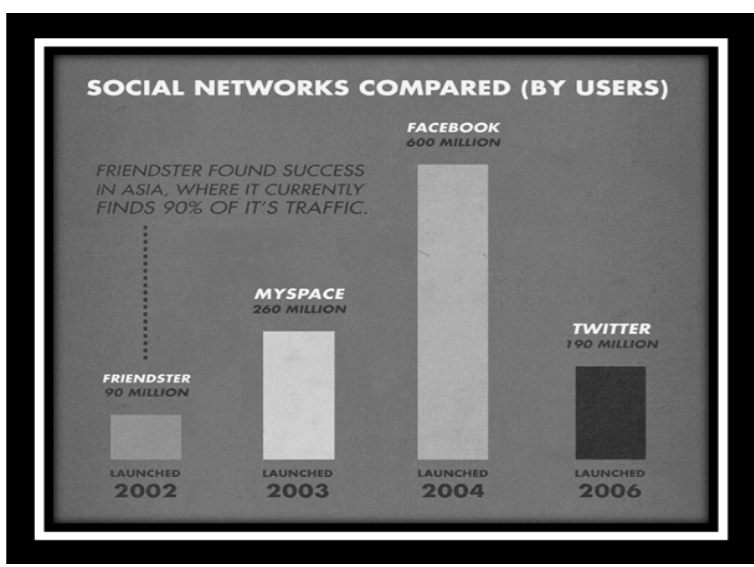

Figure 1. Most Popular Social Networks, by Number of Users 


\section{Issues in Information Systems}

Volume 14, Issue 1, pp.72-81, 2013

\section{RESEARCH METHODOLOGY}

The two main questions answered in this research are:

1 - Does the personal relationship between Saudis living in the U.S. and Saudis living in their home country become closer through the use of social networks/media?

2 - Does social networking affect Saudis living in the U.S., either positively or negatively overall?

A focus group consisting of eight Saudis living in the U.S. was held prior to distributing an online survey. The purpose of the focus group was to collect information that would guide the questions ultimately included in the survey.

\section{Focus Group}

Eight Saudis who live in the U.S. and use social networking were selected by the researchers to participate in the focus group. Some had lived in the U.S since 2006 while others lived in the country for less than one year; this provided contrasting views from people who were well acquainted with U.S. culture and those who were less acquainted. The focus group lasted 40 minutes and occurred on April 14, 2012. A structured discussion ensued about the preliminary survey questions, to check expectations about answers and test the eight participants' reaction to the results. Conversation was guided in Arabic by one of the researchers, as it was his first language and the native language of the participants. Pursuing dialogue in Arabic guaranteed that the participants fully understood the questions and allowed the researchers transcribe the final survey questions clearly in Arabic, so that the meaning would not become lost in English translation or cultural nuances. The researchers compared the participants' individual answers to the preliminary survey questions and found that some answers aligned, while others diverged among them. From this, they understood the participant's methodology and thought processes in analyzing and answering the questions.

\section{Survey Distribution}

An 18-question survey was created on SurveyMonkey.com and included questions in both English and Arabic, with one optional open-ended short answer question. The survey was distributed to Saudis residing in the U.S. through Facebook's Saudi in Pittsburgh group page (https://www.facebook.com/sshpitt?ref=ts\&fref=ts) which had at the time 819 members. An additional 40 text messages we sent via WhatsApp to 40 Saudi people residing in U.S. Another 80 personal text messages were sent by the researchers to Saudi residents U.S. The survey was open for 11 days from April 2, 2012, to April 13, 2012.

Table 1. SurveyMonkey.com Questionnaire and Answer Choices

\begin{tabular}{|c|c|}
\hline Questions & Answer Choices \\
\hline $\begin{array}{l}\text { Q1: What is your gender? } \\
\text { الجنس }\end{array}$ & $\begin{array}{l}\text { Male } \\
\text { ذكر } \\
\text { Female } \\
\text { أنثى }\end{array}$ \\
\hline $\begin{array}{l}\text { Q2: What is your age? } \\
\text { ال عקر }\end{array}$ & $\begin{array}{l}18-20 \\
21-25 \\
26-30 \\
31-35 \\
\text { Older than } 35\end{array}$ \\
\hline
\end{tabular}




\begin{tabular}{|c|c|}
\hline $\begin{array}{l}\text { Q3: What is your nationality? } \\
\text { الجنسيهب }\end{array}$ & $\begin{array}{l}\text { Saudi Arabian } \\
\text { سعودي } \\
\text { Non-Saudi } \\
\text { غير سعودي }\end{array}$ \\
\hline $\begin{array}{l}\text { Q4: Please specify your marital status. } \\
\text { الححالة الجتماعية }\end{array}$ & $\begin{array}{l}\text { Single } \\
\text { أعزب متزوج } \\
\text { Married } \\
\text { Divorced } \\
\text { مطلق }\end{array}$ \\
\hline $\begin{array}{l}\text { Q5: You are .... } \\
\text { الجرلة الدر اسية }\end{array}$ & 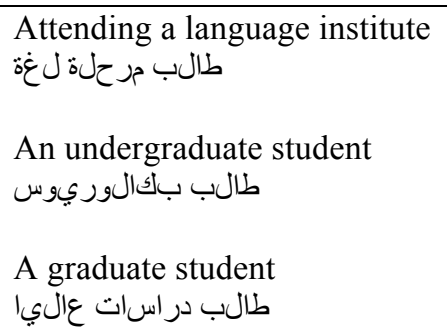 \\
\hline 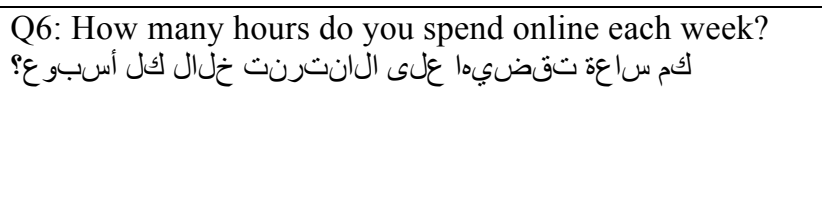 & $\begin{array}{l}0-10 \text { hours } \\
11-20 \text { hours } \\
21-30 \text { hours } \\
31-40 \text { hours } \\
\text { More than } 41 \text { hours }\end{array}$ \\
\hline 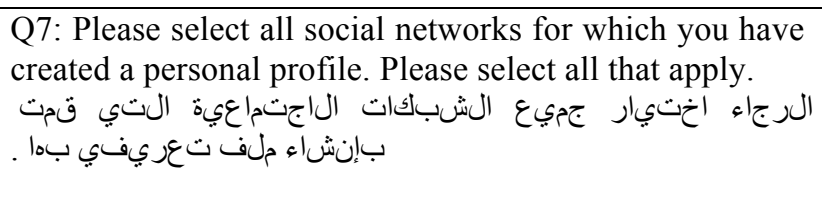 & $\begin{array}{l}\text { Facebook } \\
\text { Twitter } \\
\text { WhatsApp } \\
\text { MySpace } \\
\text { YouTube }\end{array}$ \\
\hline $\begin{array}{l}\text { Q8: How many communities/groups are you a member } \\
\text { of? } \\
\text { كم عدد المنظمات والمجهوعات التي لديك عضويه بها؟ }\end{array}$ & $\begin{array}{l}0 \\
1-10 \\
11-50 \\
51+\end{array}$ \\
\hline 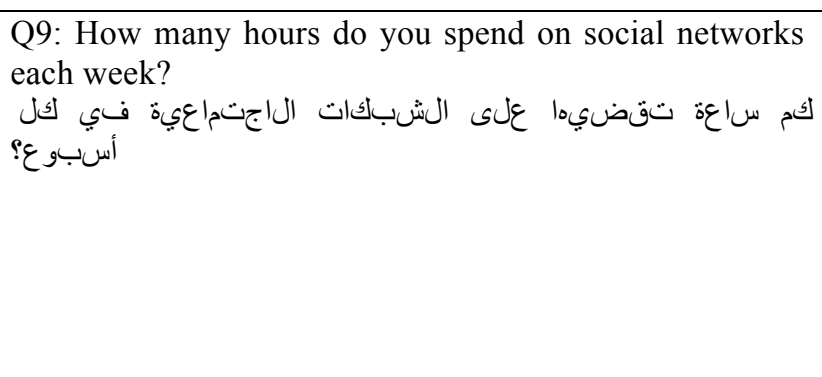 & $\begin{array}{l}0-5 \text { hours } \\
6-10 \text { hours } \\
11-15 \text { hour } \\
16-20 \text { hours } \\
21-25 \text { hours } \\
26-30 \text { hours } \\
31-35 \text { hours } \\
36-40 \text { hours } \\
\text { More than } 40 \text { hours }\end{array}$ \\
\hline
\end{tabular}




\begin{tabular}{|c|c|}
\hline 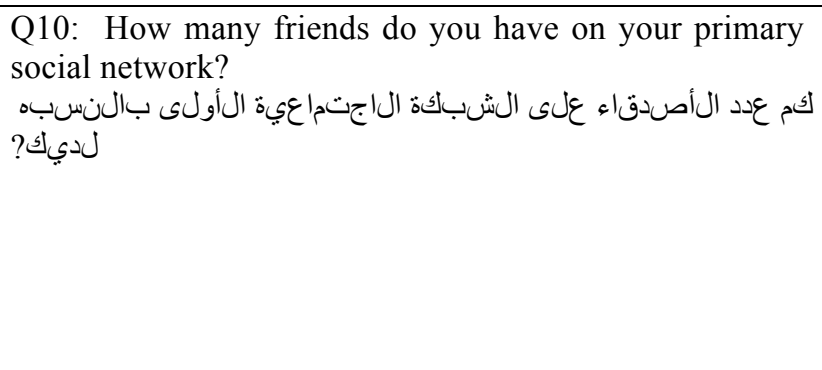 & $\begin{array}{l}1-25 \\
26-50 \\
51-75 \\
76-100 \\
101-150 \\
151-200 \\
201-300 \\
301-400 \\
\text { More than } 400\end{array}$ \\
\hline 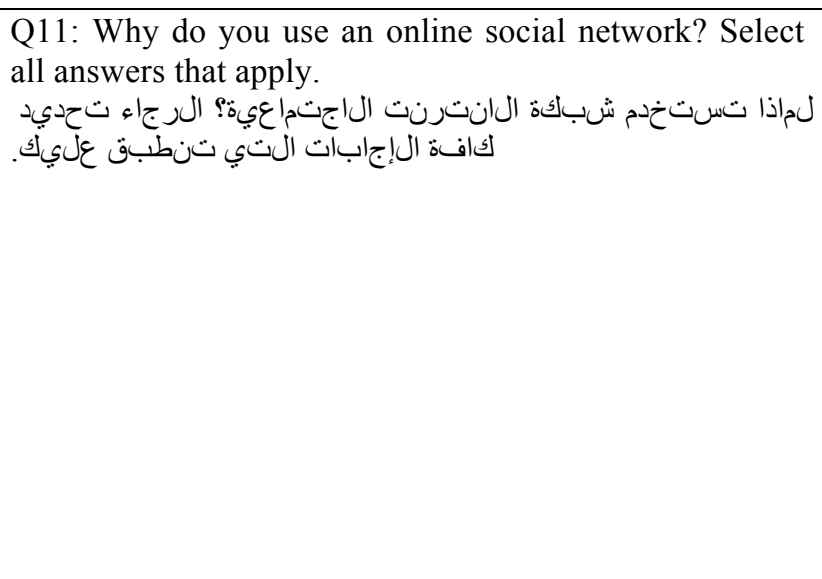 & 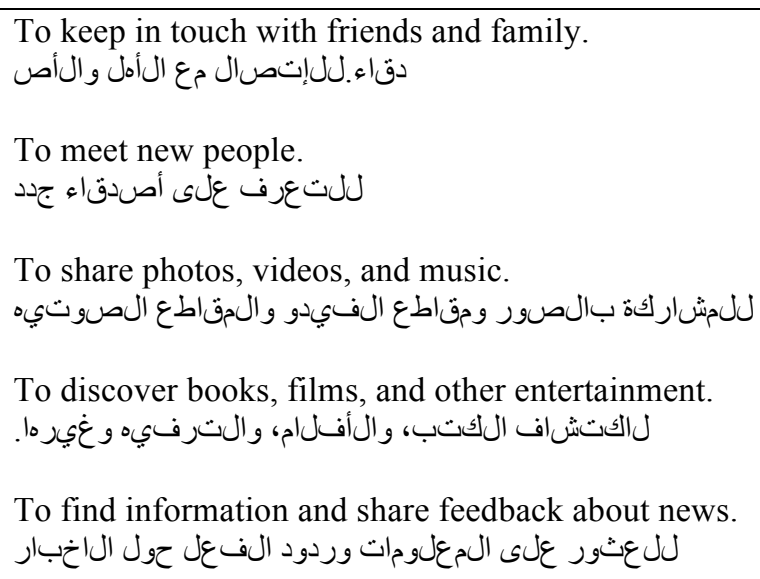 \\
\hline 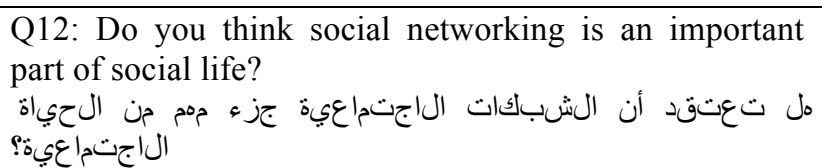 & $\begin{array}{l}\text { Yes } \\
\text { No } \\
\text { I don't know }\end{array}$ \\
\hline 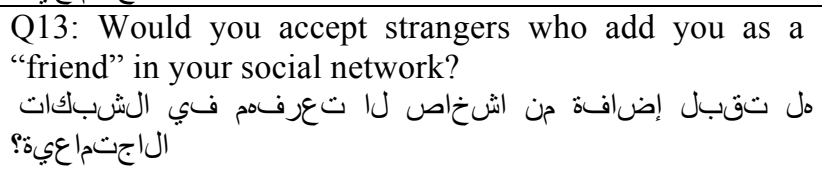 & $\begin{array}{l}\text { Yes } \\
\text { No } \\
\text { I don't know }\end{array}$ \\
\hline 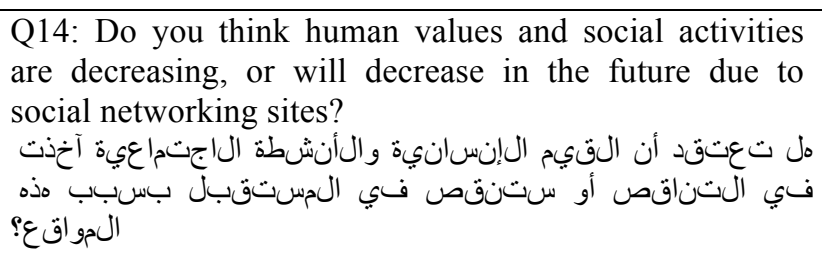 & $\begin{array}{l}\text { Yes } \\
\text { No } \\
\text { I don't know }\end{array}$ \\
\hline 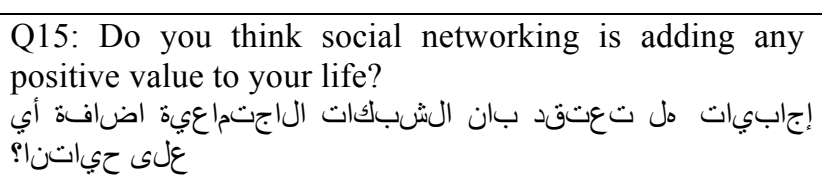 & $\begin{array}{l}\text { Yes } \\
\text { No } \\
\text { I don't know }\end{array}$ \\
\hline 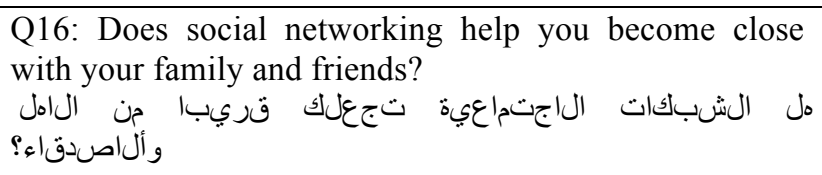 & $\begin{array}{l}\text { Yes } \\
\text { No } \\
\text { I don't know }\end{array}$ \\
\hline
\end{tabular}




\begin{tabular}{|c|c|}
\hline 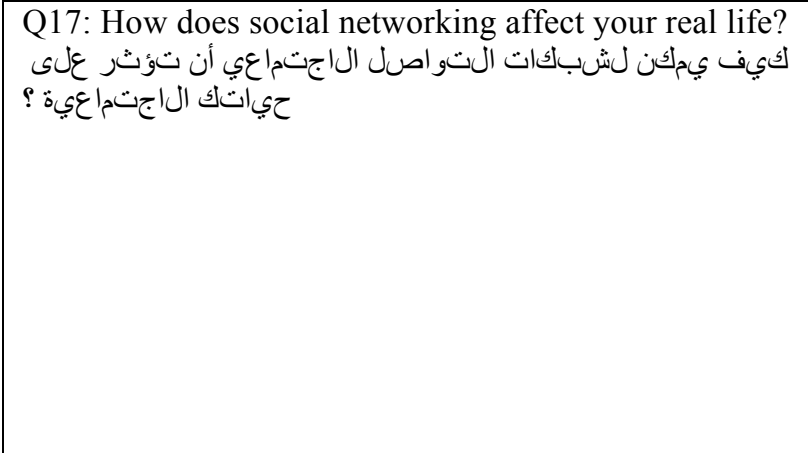 & 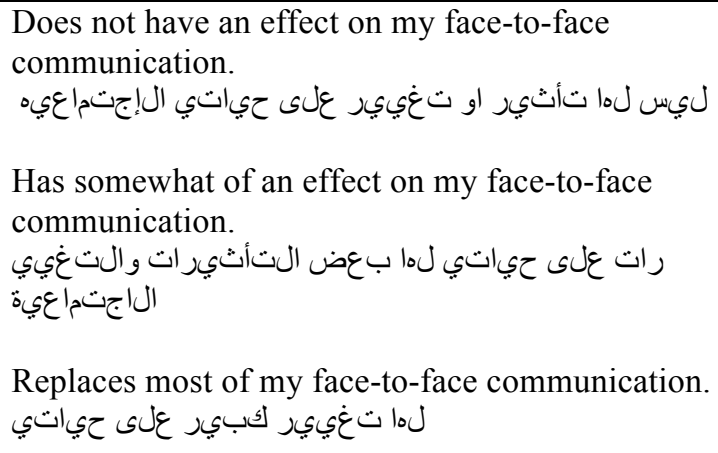 \\
\hline 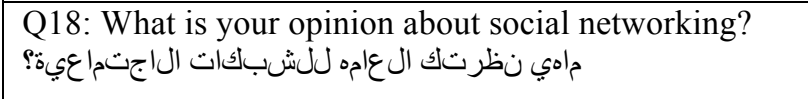 & Open-ended comment box. \\
\hline
\end{tabular}

\section{RESULTS}

The survey was completed by a total of 145 total respondents. Sixty-four people completed the optional open-ended question. Twenty of the 145 respondents did not complete the entire survey, and four respondents identified as nonSaudi. The final responses that were analyzed for the research included the remaining 121 people who fully completed the survey and identified as Saudis living in the U.S.

The survey results are as follows.

Question 1: The majority of respondents are men. $116(80.6 \%)$, were male whereas $28(19.4 \%)$ were female.

Question 2: $41.5 \%$ of respondents were between the ages of 21 and 25 and $24.6 \%$ of respondents were between the ages of 26 and 30 (Figure 2). This is significant because it shows that most Saudis who use social networks belong to a young demographic - younger than 30 .

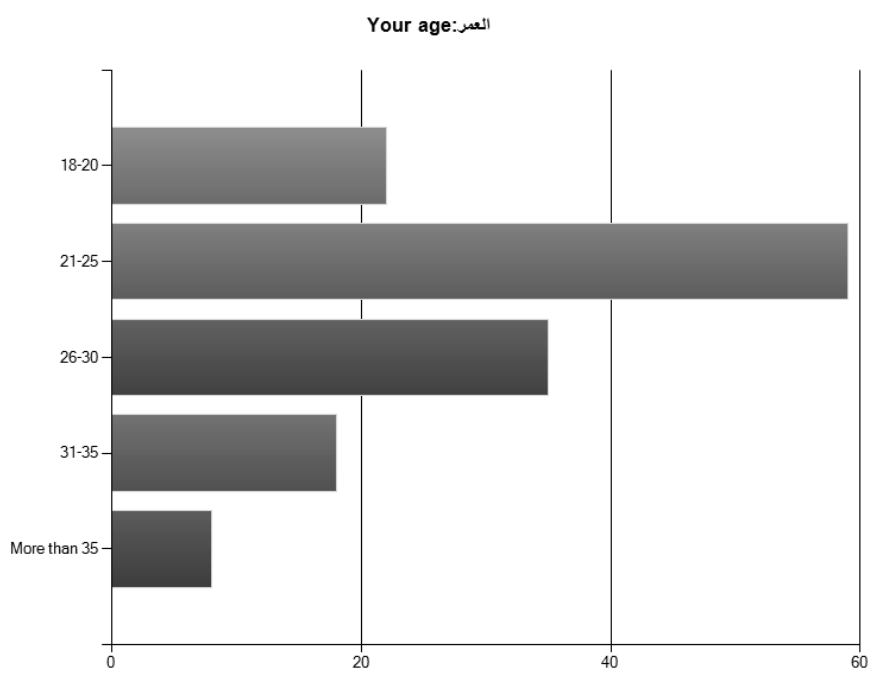

Figure 2. Ages of Survey Respondents

Question 3: Results indicate that most of the respondents identified as Saudi (97.2\%) 


\section{Issues in Information Systems}

Volume 14, Issue 1, pp.72-81, 2013

Question 4: $54.2 \%$ of participants were single, while $43.7 \%$ were married and $2.1 \%$ were divorced.

Question 5: Responses to this question were split fairly evenly, with $31 \%$ attending a language institute, $33.8 \%$ identifying as undergraduate students, and $35.2 \%$ identifying as graduate students.

Question 6: Most respondents (27.3\%) spend 0-10 hours online per week, with a close second (23.5\%) spending 1120 hours online per week. Third was $21.2 \%$ with $21-30$ hours per week, fourth was $18.2 \%$ with $31-40$ hours per week and fifth was $9.8 \%$ more than 41 hours per week.

Question 7: $96.2 \%$ of respondents created a personal profile on Facebook, followed by $84.1 \%$ who created a personal profile on WhatsApp (Figure 3). Third was You Tube at $59.8 \%$ and fourth was Twitter at $48.5 \%$. Very few respondents created a profile on MySpace (12.1\%).

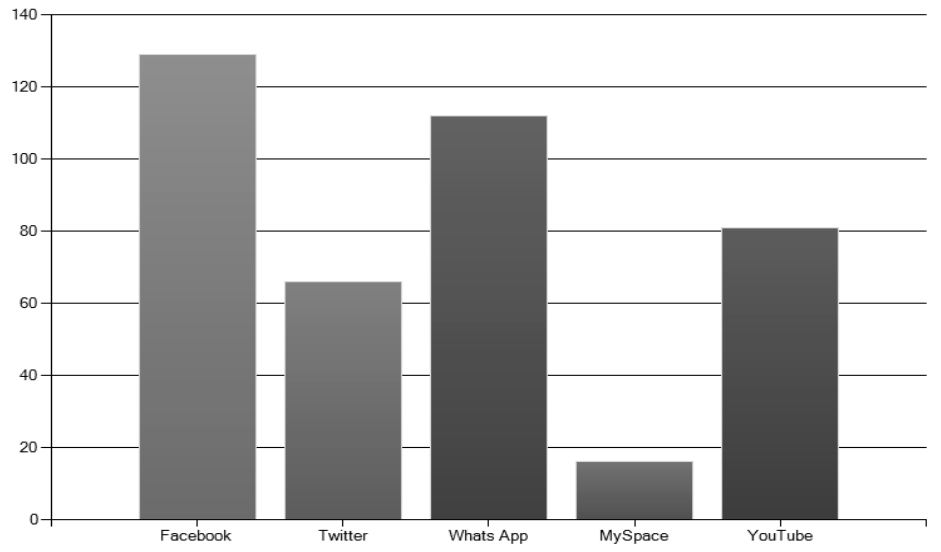

Figure 3. Social Networks on which Saudi Respondents Created a Personal Profile

Question 8: $49.2 \%$ of respondents belong to up to 10 communities or groups, while $37.9 \%$ responded "none." $10.6 \%$ of respondents belong to $11-50$ communities or groups, and $2.3 \%$ belong to more than 51 communities or groups.

Question 9: Most respondents (37.9\%) spend 0-5 hours participating in social networks each week. 18.2\% of respondents spend 6-10 hours. Those who spend 11-15 hours participating in social networks each week was $15.2 \%$. $7.6 \%$ spend $16-20$ hours per week participating in social networks.

Question 10: The majority of respondents (17.4\%) have 1-25 friends on their primary social network, while a close second majority (14.4\%) have 201-300 friends on their social network (Figure 4). 12.1\% have 101-150 friends, and $11.4 \%$ have 151-200 friends. This shows a large disparity of social network usage among respondents, between the most active and least active.

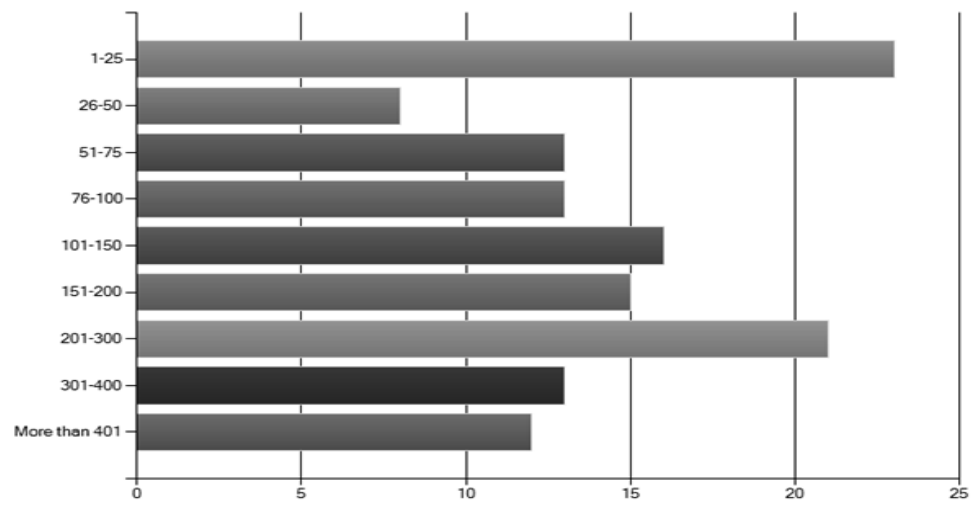




\section{Issues in Information Systems}

Volume 14, Issue 1, pp.72-81, 2013

Figure 4. Number of Friends that Saudis have on Their Primary Social Network

Question 11: Most Saudis use an social network for the purpose of keeping in touch with friends and family (91.7\%) and to share feedback about news and current events (66.7\%). 51.5\% use a social network to share photos, videos, and music. $37.1 \%$ use it to discover books, films, and other entertainment. At $28.8 \%$, only a handful of Saudis use social media to meet new people (Figure 5).

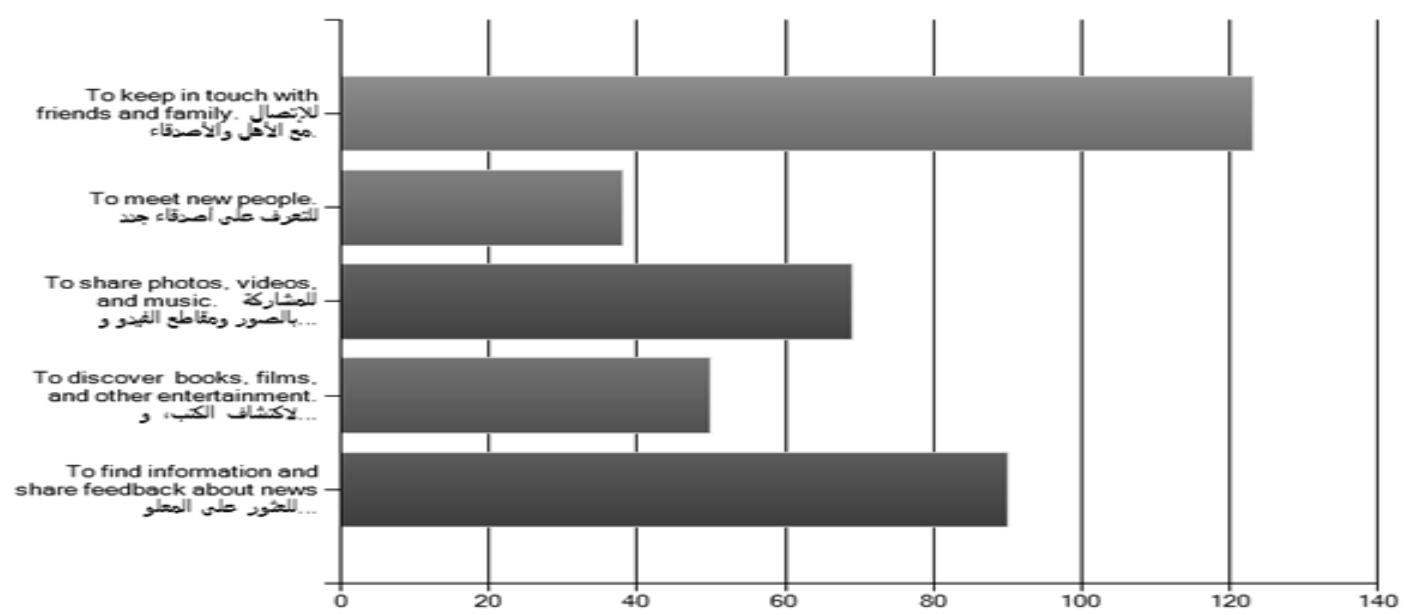

Figure 5. Saudis' Reason for Using an Online Social Network

Question 12: 83.5\% of respondents believe that social networking is an important part of their lives, while 11.2\% felt it was not, and 5.6\% did not know.

Question 13: 66.4\% of respondents would not accept a stranger as a "friend" on their social network. This data supports the responses to Question 11, that Saudis primarily use social networking for keeping in touch with their family and current friends. $19.2 \%$ would accept a stranger as a "friend," and $14.4 \%$ did no know.

Question 14: 44.8\% of Saudis believe that human values and social activities are decreasing or will decrease in the future, due to increased use of social networking. $36 \%$ disagree with this statement, and $19.2 \%$ are unsure.

Question 15: While the majority of answers to Question 14 indicate that social networking may have a negative effect on humanity as a whole, $86.6 \%$ of respondents to Question 15 believe that social networking is actually a positive influence in their own lives.

Question 16: $90.4 \%$ of respondents believe that social networking has helped them foster relationships with their families and friends. While only $6.4 \%$ felt it does not and only $3.2 \%$ did not know.

Question 17: Most Saudis (72.1\%) indicate that social networking has only "somewhat affected" their face-to-face communication and personal interaction with others (Figure 7). While 17.2\% indicated that social networking does not have an affect on face to face communications and $10.7 \%$ indicated that social networking replaces most face to face communications. 


\section{Issues in Information Systems}

Volume 14, Issue 1, pp.72-81, 2013

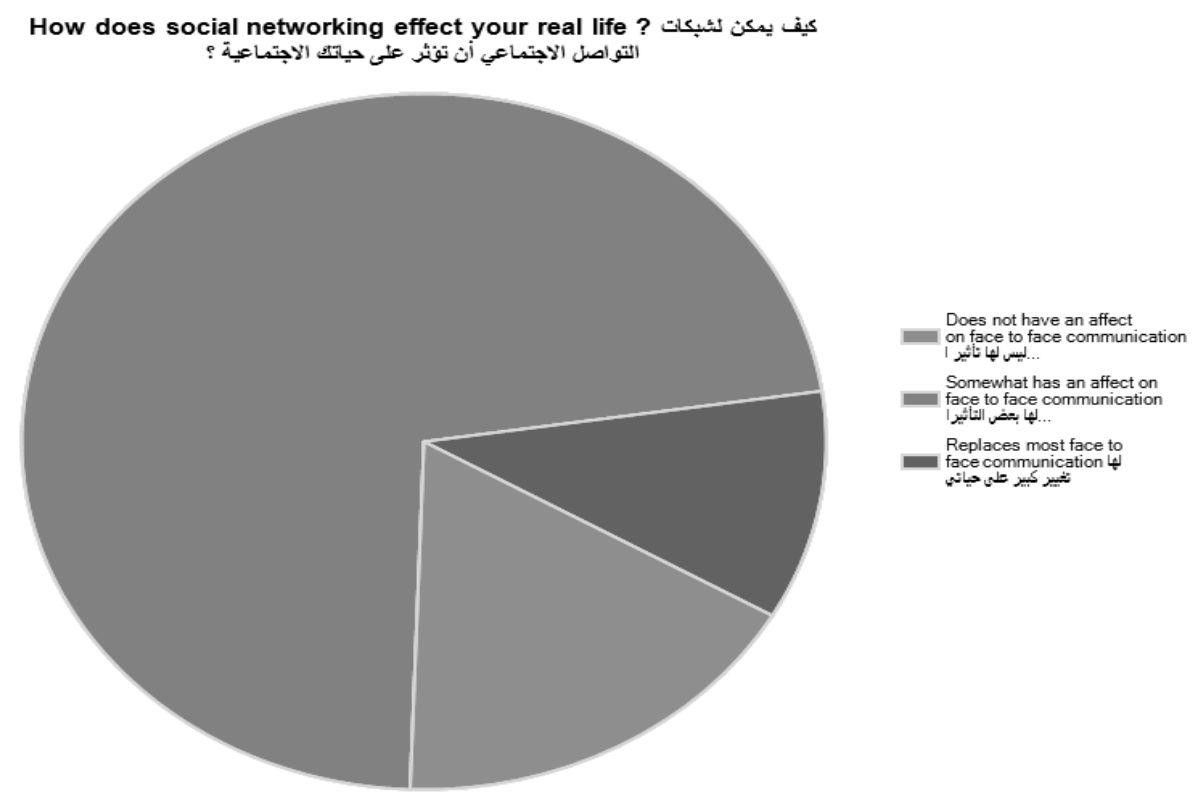

Figure 6. Affect of Social Networking on Saudis' Face-to-Face Communication

Question 18: This was the only open-ended question on the survey, which asked survey takers what their opinion was about social networking. None of the respondents who answered this question explicitly stated that social media was either good or bad, but some thought it had both positive and negative aspects to it. An example of responses is below.

"It has both positive and negative impacts, with more negatives than positives; they have some advantages and more disadvantages."

"It has its pros and cons but I think its pros are more than its cons."

"Everything has cons and pros... so, it in one way makes the world a better place. However, it has a lot of bad influences on a non-educated user. It all depends on the user."

\section{CONCLUSIONS}

According to the data from this study, Saudis living in the U.S. have mostly unified opinions about the social media tools that they use, and the affect of social networking in their own lives and on society at large. However, there are some areas where their answers diverged, particularly in Question 18. Responses to this question ranged from opinions that social networking has more positive effects than negative effects, to opinions that the effect of social networking depends on the type of person participating. To assess how social networking influences a typical Saudi's real social activities and values, we must place emphasis on the responses to this question.

$41.1 \%$ of respondents believed that social networking degrades personal relationship bonds, because these social activities are a very important part in Saudi culture and cannot be ignored. According to one of the responses, which written in Arabic and translated to English: "Social networking has many positive effects to the Saudis who live out of Saudi Arabia, though it may affect people's behaviors as it results in less real social connection."

Conversely, many responses to the same question indicate that social networking has a positive influence and adds benefits to Saudi life, such as communicating with family and friends, opening different cultures to each other, and making social relationships stronger. The combined essence of three responses (written in Arabic and translated to English) indicated that, despite the long distance between Saudis living in the U.S. and their families living in Saudi 


\section{Issues in Information Systems}

Volume 14, Issue 1, pp.72-81, 2013

Arabia, they feel like they are geographically closer just through their use of social media. Indeed, the vast majority of responses to questions on the survey indicate that keeping in touch with friends and family are important to Saudis.

Social media has been determined by Saudis to be a convenient, cost-efficient, and effective way to build new connections and foster existing relationships overseas. This finding is likely not exclusive to Saudi people; it may be applied to people from other countries whose culture is family-oriented and places high value on frequent social interaction. Social networking offers a wide array of features, regardless of some disadvantages, such as the potential for decreasing human face-to-face contact. The popularity of social networking tools continues to rise, and people continue to adjust their lives accordingly to reap the greatest benefits these tools have to offer.

\section{REFERENCES}

Abratt, R., Nel D., \& Higgs, S. N.(1992). An examination of the ethical beliefs of managers using selected scenarios in a cross-cultural environment. Journal of Business Ethics, 11(1), 29-35.

Benham, H. C., \& Wagner, J. L. (1995). Ethical attitudes of business students and MIS personnel. Proceedings of the ACM SIGCPR Conference [online], Nashville TN USA, 44-49. Retrieved from www.acm.org/pubs/articles/proceedings/cpr/212490/p44-wagner/p44-wagner.pdf

Boyd, D. M., \& Ellison, N. B. (2007). Social Network Sites: Definition, history, and scholarship. Journal of Computer-Mediated Communication, 13(1), article 11. Retrieved from http://jcmc.indiana.edu/vol13/issue1/boyd.ellison.html on February 11, 2013.

Gates, B. (1995). The road ahead. New York, NY: Viking Penguin Group.

Ghanem, R. (2012, September 24). Social media connecting people. Saudi Gazette. Retrieved from http://www.saudigazette.com.sa/index.cfm?method=home.regcon\&contentid=20120924137282

The history of social networking. (2010). Retrieved February 11, 2013, from http://www.onlineschools.org/blog/history-of-social-networking/.

How do you use social media? Retrieved from http://www.surveymonkey.com/s/993XQZH.

jhoyt1123. (2010, September 13). Social Networking Survey. Retrieved from http://www.quibblo.com/quiz/dJelep0/Social-Networking-Survey.

Menzies, Heather. (1999). Digital networks: the medium of globalization and the message. Canadian Journal of Communication., 24(4), 539-539. Retrieved from http://search.proquest.com/docview/219573788?accountid=28365

Simon, M. (2009). The Complete History of Social Networking: CBBS to Twitter. Retrieved February 12, 2013, from http://www.maclife.com/article/feature/complete_history_social_networking_cbbs_twitter

Social networking and their affect to families. [Translated.] مجلة البئل الباتصال الحديثة] . [وتأثيرها على السرة. Retrieved from http://www.albayan.co.uk/article.aspx?id=497 